\begin{tabular}{|c|c|}
\hline Title & Diffusive thermal effect on local chemical structures in premixed hydrogen-air flames \\
\hline Author(s) & Matsugi, A kira; Terashima, Hiroshi \\
\hline Citation & $\begin{array}{l}\text { Combustion and flame, 179, } 238-241 \\
\text { https://doi.org/10.1016/.combustflame.2017.02.013 }\end{array}$ \\
\hline Issue Date & $2017-05$ \\
\hline Doc URL & http:/hdl .handle.net/2115/73811 \\
\hline Rights & $\begin{array}{l}\text { @ 2017. This manuscript version is made available under the CC-BY-NC-ND } 4.0 \text { license } \\
\text { http://creativecommons.org/icenses/by-nc-nd/4.0/ }\end{array}$ \\
\hline Rights(URL) & http://creativecommons.org/icenses/by-nc-nd/4.0/ \\
\hline Type & article (author version) \\
\hline File Information & HUSCAP_rfinal_manuscript.pdf \\
\hline
\end{tabular}

Instructions for use 


\title{
Diffusive-thermal effect on local chemical structures in premixed hydrogen-air flames
}

\author{
Akira Matsugi $^{\mathrm{a} *}$ and Hiroshi Terashima ${ }^{\mathrm{b}, \mathrm{c} *}$ \\ ${ }^{a}$ National Institute of Advanced Industrial Science and Technology (AIST), 16-1 Onogawa, \\ Tsukuba, Ibaraki 305-8569, Japan. \\ ${ }^{b}$ The University of Tokyo, 2-11-16 Yayoi, Bunkyo, Tokyo 113-8656, Japan. \\ ${ }^{c}$ Hokkaido University, N13 W8, Kita-ku, Sapporo, Hokkaido 060-8628, Japan. \\ * Corresponding authors. E-mail addresses: a.matsugi@aist.go.jp (A. Matsugi), \\ htera@eng.hokudai.ac.jp (H. Terashima).
}

Article type: Brief Communication

Length: 109 words (abstract); 1417 words (main text); 5 figures

\section{Abstract}

The diffusive-thermal effect plays an important role in the intrinsic instability of premixed flames. A two-dimensional direct numerical simulation of the propagation of premixed hydrogen-air flames was performed using a detailed chemical kinetics model. The cellular behavior of a lean hydrogen-air flame was analyzed on the basis of its chemical structure. The primary consequence of the diffusive-thermal effect was found to be a change in the buildup process of reactive intermediates by the chain reaction mechanism at the preheat zone. The resultant chemical structure at the main reaction zone can be explained by the local composition change of the gas flowing into the reaction zone from the preheat zone.

Keywords: Flame instability; Diffusive-thermal effect; Direct numerical simulation; Chemical kinetics 


\section{Introduction}

The intrinsic instability of premixed flames [1-4] affects its shape and structure, resulting in the formation of a cellular flame front and the acceleration of flame speed. Hydrodynamic instability caused by thermal expansion is a ubiquitous and essential factor in the flame instability. In addition, the diffusive-thermal effect due to nonequidiffusion of mass and heat also plays a major role depending on the Lewis number of reactants. Detailed mechanistic understanding of these effects is of fundamental interest in combustion studies.

Dynamics of unstable flames have been the subject of many numerical investigations, from which considerable phenomenological insight has been obtained [5-12]. Nevertheless, only a few studies have reported on the role of chemical reactions in flame instability (e.g. $[6,10,12])$. In principle, reaction kinetics plays a minimal role in hydrodynamic instability and therefore the increment of flame velocity can be interpreted as a consequence of increased flame surface area. The diffusive-thermal effect influences the gas composition supplied to the flames and induces spatial variations of the reaction rate [7], which can further destabilizes the flame when the Lewis number is sufficiently low. Although this variation results in a further change in the flame velocity, the role of chemical processes on the acceleration mechanisms remains uncertain.

The present study aims to provide further mechanistic insight into the chemistry involved in the diffusive-thermal effect. Numerical simulations were performed for two-dimensional hydrogen-air flames using a detailed kinetic model. The results were analyzed from the viewpoint of chemical structure to uncover underlying chemical mechanism responsible for the instability. 


\section{Method}

Free propagation of the two-dimensional premix hydrogen-air flame was simulated with the Navier-Stokes equations on a rectangular domain with a fixed length of $-L / 2 \leq x \leq L / 2$ and a fixed height of $0 \leq y \leq h$, where $L=10.0 \mathrm{~cm}$ and $h=0.4 \mathrm{~cm}$. Detailed descriptions on the computational method with relevant references [13-20] are given in the supplemental material. The premixed hydrogen-air mixtures at equivalence ratios of $\phi=0.5$ and 1.0 entered the domain from the left $(x<0)$ boundary at a uniform unburned gas temperature $\left(T_{\mathrm{u}}=300\right.$ $\mathrm{K}$ ), pressure ( $p=1 \mathrm{~atm}$ ), and velocity (laminar flame velocity, $S_{\mathrm{L}}$ ). The boundary for the outflow is the non-reflecting condition. Periodic boundary conditions were imposed in the $y$-direction. As an initial condition, a steady planar flame structure was placed on the domain and perturbed by a sinusoidal disturbance with amplitude of $0.004 \mathrm{~cm}$ and wavelength equal to the domain height. As a reference, one-dimensional (or planar) laminar flame speed, structure, and flame thickness $\left(\delta_{\mathrm{T}} \equiv\left(T_{\mathrm{b}}-T_{\mathrm{u}}\right) /(\mathrm{d} T / \mathrm{d} x)_{\max }\right.$ where $T_{\mathrm{b}}$ is the adiabatic flame temperature and $(\mathrm{d} T / \mathrm{d} x)_{\max }$ is the maximum temperature gradient) were also calculated using the Cantera program [19].

\section{Results and Discussion}

Temporal evolution of the flame fronts is shown in Fig. 1. Here, the flame fronts are defined as isolines of temperature as $T=\left(T_{\mathrm{u}}+T_{\mathrm{b}}\right) / 2$. The $\phi=1.0$ flame quickly evolved to a single-cell structure that stably propagated upstream, whereas formation of the secondary cell was observed for the $\phi=0.5$ flame.

Figure 2 shows the time history of the normalized flame velocity ( $S_{\text {cf }}$; calculated as the burning rate integrated over the whole computational domain and normalized by the planar flame value), the normalized length of the flame front ( $L_{\mathrm{cf}}$; normalized by the planar flame 
value), and their ratio. As expected, the normalized velocity is approximately equal to the normalized flame front length for the $\phi=1.0$ flame because the hydrodynamic effect dominates the cellular structure of this flame. On the other hand, the cell formation in the $\phi=$ 0.5 flame also increases the velocity but the increment cannot solely be accounted for by elongation of the flame front, suggesting some changes of chemical reaction structure along the flame. Local spatial profiles of the temperature and major species fractions at the top of the convex (toward the unburned gas) front and at the bottom of the concave front in the $\phi=$ 0.5 flame are shown in Figs. 3 and 4, respectively. The profiles are taken to be normal to the flame front and plotted along the relative distance $x^{\prime}$. The profiles differ from those of the 1-D flame shown as solid lines. The diffusive-thermal effect preferably supplies $\mathrm{H}_{2}$ to the convex side of the flame, which increases/decreases the reactivity of mixtures (and hence the temperature) at the crest/trough part of the flame.

The concentration of radicals build up in the preheat zone of the flame due to the well-known chain reaction mechanism:

$$
\begin{aligned}
& \mathrm{H}+\mathrm{O}_{2}=\mathrm{HO}_{2} \\
& \mathrm{H}+\mathrm{O}_{2}=\mathrm{OH}+\mathrm{O} \\
& \mathrm{O}+\mathrm{H}_{2}=\mathrm{OH}+\mathrm{H} \\
& \mathrm{OH}+\mathrm{H}_{2}=\mathrm{H}_{2} \mathrm{O}+\mathrm{H}
\end{aligned}
$$

In this region, the rate of each reaction is pseudo-first-order since there exist large excess amounts of $\mathrm{H}_{2}$ and $\mathrm{O}_{2}$ relative to the radicals. Thereby, the preferable diffusion of $\mathrm{H}_{2}$ toward the convex part affects the buildup rate of the chain carriers. The chain reactions continue until the consumption of $\mathrm{H}_{2}$ reaches a certain level. Then, the main heat release occurs by consumption of the chain carrier radicals, $\mathrm{HO}_{2}$, and $\mathrm{H}_{2} \mathrm{O}_{2}$ mainly through the reactions:

$$
\begin{aligned}
& \mathrm{H}+\mathrm{O}_{2}=\mathrm{HO}_{2} \\
& \mathrm{O}+\mathrm{H}_{2} \mathrm{O}=\mathrm{OH}+\mathrm{OH}
\end{aligned}
$$




$$
\begin{aligned}
& \mathrm{OH}+\mathrm{HO}_{2}=\mathrm{H}_{2} \mathrm{O}+\mathrm{O}_{2} \\
& \mathrm{OH}+\mathrm{H}_{2} \mathrm{O}_{2}=\mathrm{H}_{2} \mathrm{O}+\mathrm{HO}_{2}
\end{aligned}
$$

This region can be considered as the main reaction zone since most of the heat is released at this stage. Importantly, the heat release rates of these reactions are not affected by the concentration of $\mathrm{H}_{2}$; the kinetics here is insensitive to the amount of $\mathrm{H}_{2}$ supplied to the main reaction zone. Therefore, the primary consequence of the preferable diffusion of $\mathrm{H}_{2}$ is the change in the buildup process of the reactive intermediates at the preheat zone.

The above consideration suggests that the reaction and heat release rates at the main reaction zone can be determined from the gas composition of the mixture provided from the preheat zone. As previously noted, the chain reactions proceed with pseudo-first-order at the preheat zone; hence, the composition should reflect the amount of $\mathrm{H}_{2}$ (and $\mathrm{O}_{2}$ ) consumed there. This indicates that the chemistry at the main reaction zone is similar to that of the 1-D premixed flame with different equivalence ratio. To validate this hypothesis, the corresponding effective equivalence ratio, $\phi_{\mathrm{eff}}$, was calculated on the basis of the peak concentration of $\mathrm{H}$ atoms $\left([\mathrm{H}]_{\max }\right)$; namely, the relationship between $[\mathrm{H}]_{\max }$ and the equivalence ratio was determined from the 1-D premixed flame calculations, which was used as a calibration curve to estimate $\phi_{\text {eff }}$ from $[\mathrm{H}]_{\max }$. The resultant $\phi_{\text {eff }}$ was, respectively, 0.56 and 0.44 at the crest and trough part of the 2-D flame at $\phi=0.5$. The dashed lines in Figs. 3 and 4 represent the profiles of the 1-D flames at these effective equivalence ratios. Their values and shapes essentially agree with the profiles in the 2-D flame. Some deviations at downstream of the trough parts are caused by the mass and heat transport in the non-uniform burnt gas region that does not influence the chemistry at the main reaction zone. Therefore, the local chemical structure of this 2-D flame can be explained by the composition changes of the gas flowing into the reaction zone from the preheat zone.

Finally, Fig. 5 shows the distribution of $\phi_{\text {eff }}$ along the flame front and the corresponding 
laminar flame velocity relative to that at $\phi=0.5$. The average of the latter value along the flame front was 1.22 , which is larger than unity because the convex parts spatially dominate the flame front due to the expansion of burnt gas behind the leading front. This value can account for the increment of the flame velocity beyond the surface area increment shown in Fig. 2. This result indicates that the increment is dominantly caused by changes in the chemistry at the main reaction zone that can be represented using the effective equivalence ratios.

To conclude, this Brief Communication proposed the novel interpretation regarding the chemical mechanism involved in the diffusive-thermal instability effect of the premixed flames: the primary consequence of the effect is spatial modulation in the radical buildup behavior at the preheat zone, which results in local composition variation at the main reaction zone. This interpretation also suggests that the diffusive-thermal instability cannot be properly described when single-step reaction scheme is employed since such scheme has no clear mechanistic distinction between the radical buildup and heat release processes.

\section{Acknowledgments}

The computations were conducted using the PRIMEHPC FX10 System at the Information Technology Center of The University of Tokyo.

\section{Supplementary material}

Computational details and the kinetic model, thermodynamic data, and transport properties used in the calculation. 


\section{References}

[1] P. Clavin, Dynamic behavior of premixed flame fronts in laminar and turbulent flows, Prog. Energy Combust. Sci. 11 (1985) 1-59.

[2] V.V. Bychkov, M.A. Liberman, Dynamics and stability of premixed flames, Phys. Rep. 325 (2000) 115-237.

[3] G.I. Sivashinsky, Some developments in premixed combustion modeling, Proc. Combust. Inst. 29 (2002) 1737-1761.

[4] M. Matalon, Flame dynamics, Proc. Combust. Inst. 32 (2009) 57-82.

[5] G. Patnaik, K. Kailasanath, E.S. Oran, K.J. Laskey, Detailed numerical simulations of cellular flames, Proc. Combust. Inst. 22 (1989) 1517-1526.

[6] G. Patnaik, K. Kailasanath, Numerical simulations of burner-stabilized hydrogen-air flames in microgravity, Combust. Flame 99 (1994) 247-253.

[7] S. Kadowaki, Flame Velocity of Cellular Flames at Low Lewis Numbers, Combust. Sci. Tech. 162 (2001) 223-234.

[8] S. Kadowaki, H. Suzuki, H. Kobayashi, The unstable behavior of cellular premixed flames induced by intrinsic instability, Proc. Combust. Inst. 30 (2005) 169-176.

[9] S. Kadowaki, T. Hasegawa, Numerical simulation of dynamics of premixed flames: flame instability and vortex?flame interaction, Prog. Energy Combust. Sci. 31 (2005) 193-241.

[10] G.J. Sharpe, S.A.E.G. Falle, Numerical simulations of premixed flame cellular instability for a simple chain-branching model, Combust. Flame 158 (2011) 925-934.

[11] C.E. Frouzakis, N. Fogla, A.G. Tomboulides, C. Altantzis, M. Matalon, Numerical study of unstable hydrogen/air flames: Shape and propagation speed, Proc. Combust. Inst. 35 (2015) 1087-1095.

[12] C. Altantzis, C.E. Frouzakis, A.G. Tomboulides, K. Boulouchos, Direct numerical simulation of circular expanding premixed flames in a lean quiescent hydrogen-air mixture: Phenomenology and detailed flame front analysis, Combust. Flame 162 (2015) 331-344.

[13] H. Terashima, M. Koshi, C. Miwada, T. Mogi, R. Dobashi, Effects of initial diaphragm shape on spontaneous ignition of high-pressure hydrogen in a two-dimensional duct, Int. J. Hydrog. Energy 39 (2014) 6013-6023. 
[14] Y. Morii, H. Terashima, M. Koshi, T. Shimizu, E. Shima, ERENA: A fast and robust Jacobian-free integration method for ordinary differential equations of chemical kinetics, J. Comput. Phys. 322 (2016) 547-558.

[15] H. Terashima, M. Koshi, Mechanisms of strong pressure wave generation in end-gas autoignition during knocking combustion, Combust. Flame 162 (2015) 1944-1956.

[16] K. Shimizu, A. Hibi, M. Koshi, Y. Morii, N. Tsuboi, Updated kinetic mechanism for high-pressure hydrogen combustion, J. Propul. Power 27 (2011) 383-395.

[17] R. Kee, F. Ruply, J. Miller, Chemkin-II: A Fortran Chemical Kinetics Package for the Analysis of Gas-Phase Chemical Kinetics, Sandia Report SAND89-8009, 1989.

[18] R. Kee, G. Dixon-Lewis, J. Warnatz, M. Coltrin, J. Miller, A Fortran Computer Code Package for the Evaluation of Gas-Phase, Multicomponent Transport Properties, SAND86-8246, 1986.

[19] D. G. Goodwin, H. K. Moffat, R. L. Speth. Cantera: An object-oriented software toolkit for chemical kinetics, thermodynamics, and transport processes <http://www.cantera.org>, Version 2.1, 2014.

[20] K. W. Thompson, Time dependent boundary conditions for hyperbolic systems, J. Comput. Phys. 68 (1987) 1-24. 


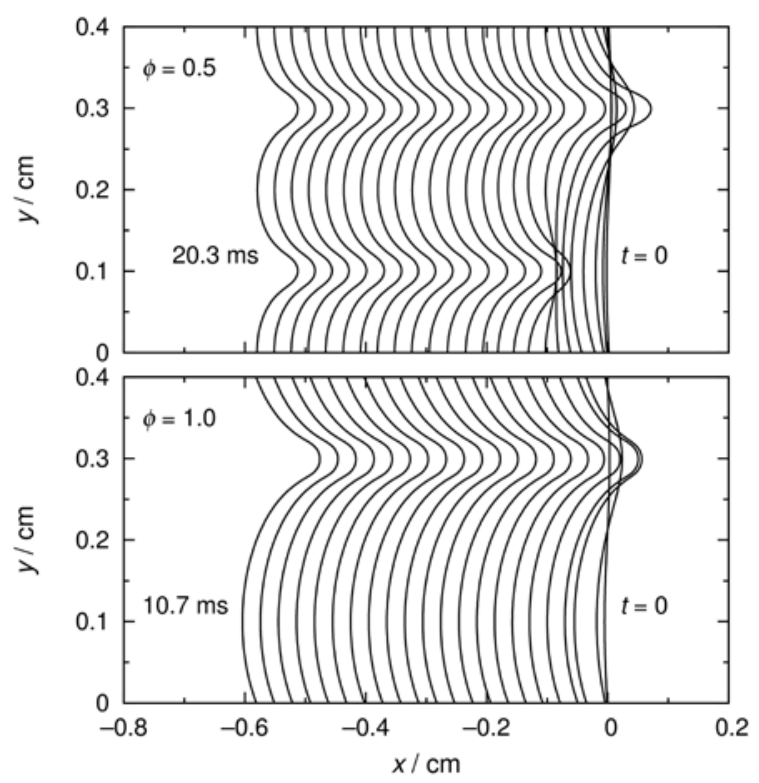

Fig. 1 Time evolution of the flame front of the hydrogen-air flames at $\phi=0.5$ and 1.0.
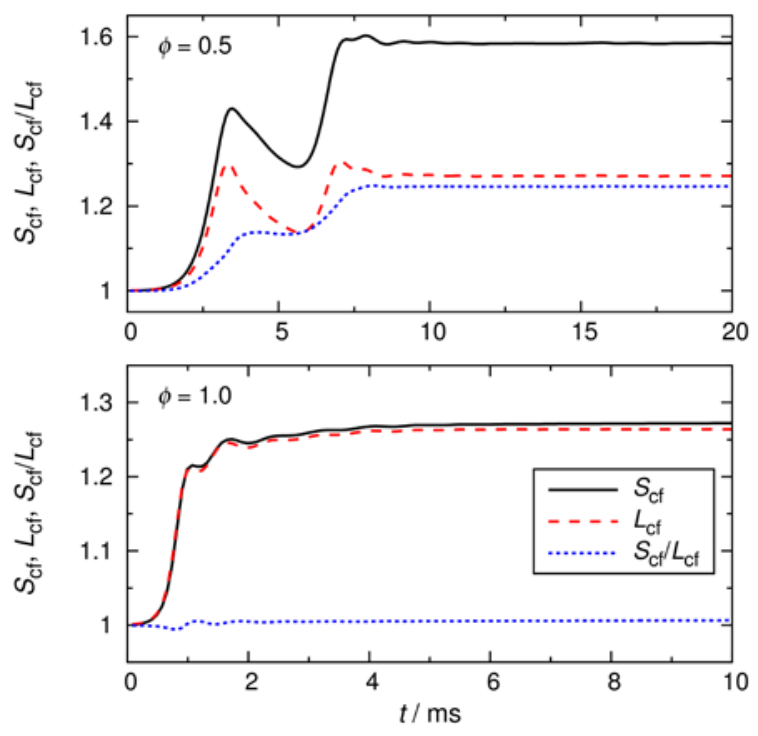

Fig. 2 Time history of the normalized burning velocity $\left(S_{\mathrm{cf}}\right)$, normalized flame front length $\left(L_{\mathrm{cf}}\right)$, and their ratio $\left(S_{\mathrm{c}} / L_{\mathrm{cf}}\right)$ of the hydrogen-air flames at $\phi=0.5$ and 1.0. 


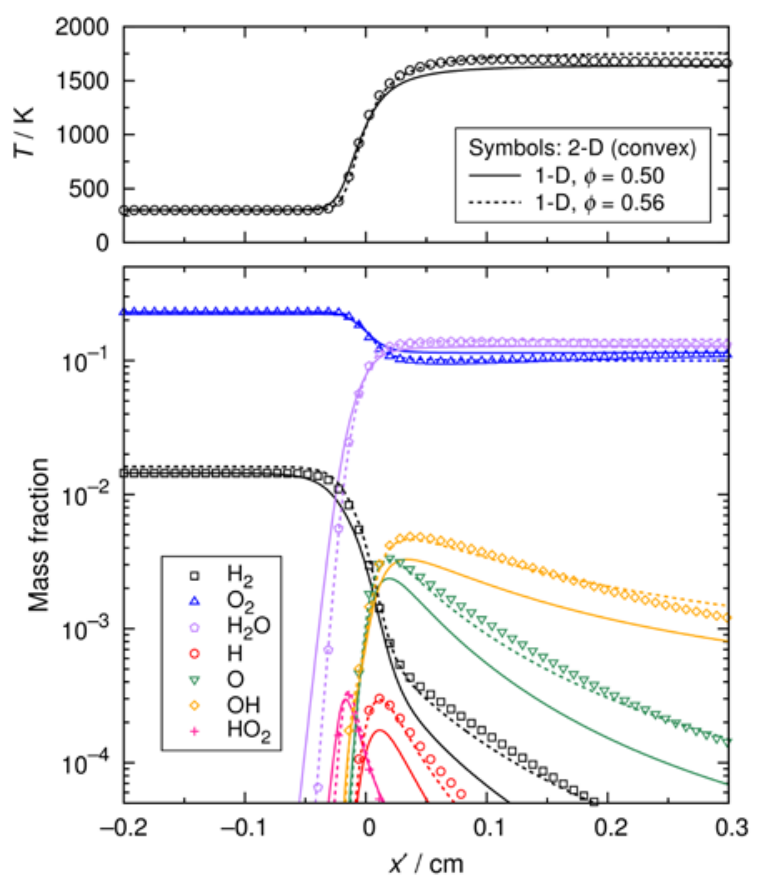

Fig. 3 Local spatial profiles of the temperature and major species fractions at the top of the convex front in the $\phi=0.5$ flame at $t=10 \mathrm{~ms}$ (Symbols; only every third data point is shown for clarity). The profiles for the 1-D flames at $\phi=0.5$ and 0.56 are also shown as solid and dashed lines, respectively.

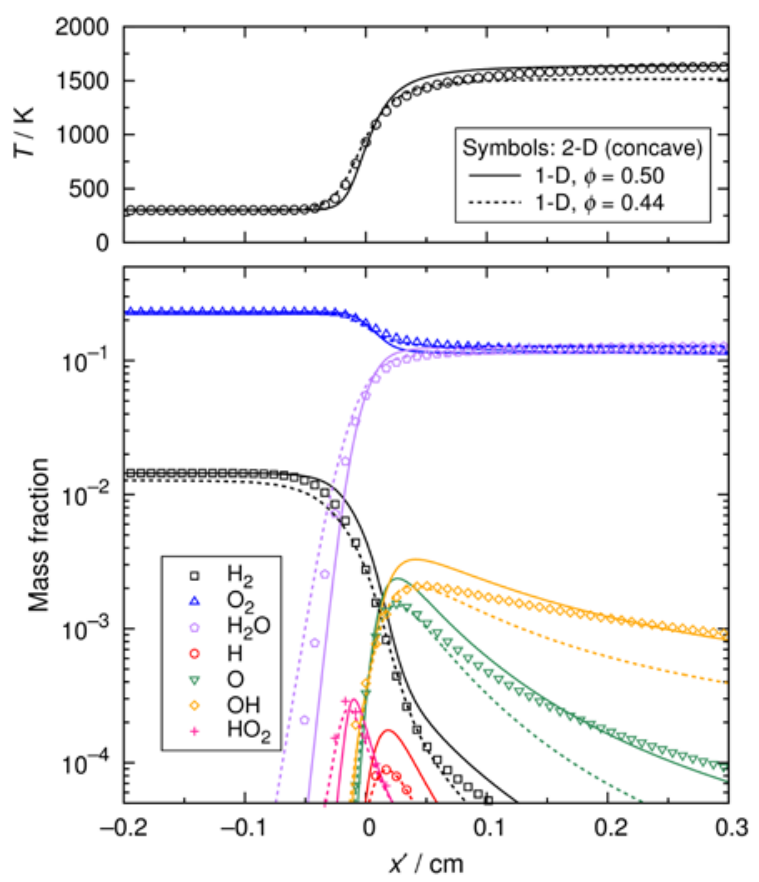

Fig. 4 Local spatial profiles of the temperature and major species fractions at the bottom of the concave front in the $\phi=0.5$ flame at $t=10 \mathrm{~ms}$ (Symbols; only every third data point is shown for clarity). The profiles for the 1 -D flames at $\phi=0.5$ and 0.44 are also shown as solid and dashed lines, respectively. 

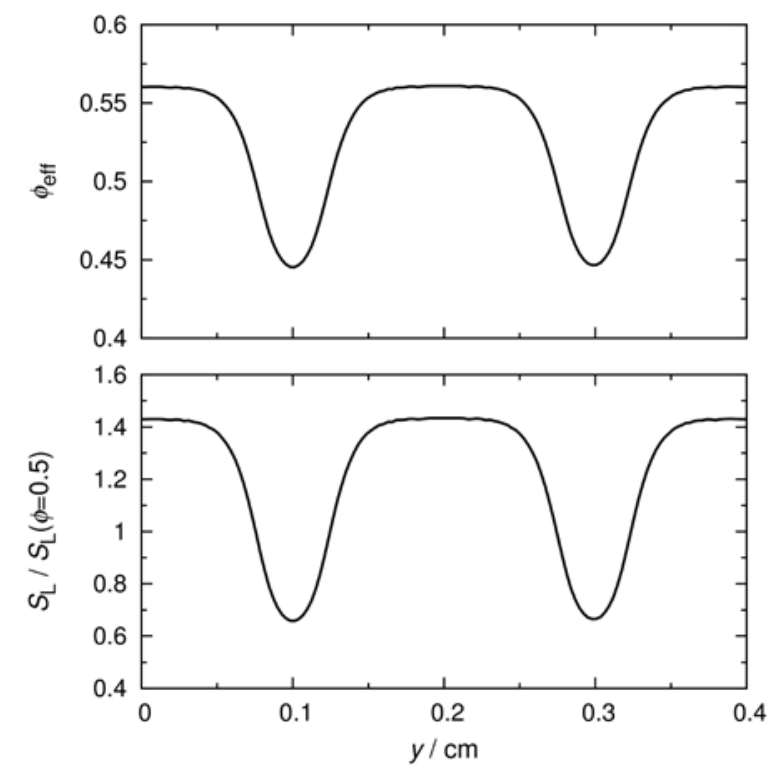

Fig. 5 Spatial distribution of $\phi_{\text {eff }}$ along the flame front and corresponding laminar flame velocity (relative to that at $\phi=0.5$ ) in the $\phi=0.5$ flame at $t=10 \mathrm{~ms}$. 